\title{
Gallium Ga 68 NODAGA-CBP8
}

National Cancer Institute

\section{Source}

National Cancer Institute. Gallium Ga 68 NODAGA-CBP8. NCI Thesaurus. Code C157635.

A radiotracer composed of $\mathrm{CBP} 8$, a collagen-targ eting peptide, linked via a tris(tert-butyl) ester-protected 1,4,7-triazacyclononane,1-glutaric acid-4,7-acetic acid (NODAGA) chelator, to the radioisotope gallium Ga 68 , with potential imaging activity upon positron emission tomography/computed tomography (PET/CT). Upon administration, gallium Ga 68 NODAGA-CBP8 selectively binds with high affinity to collagen type 1. Upon PET/CT imaging, gallium Ga 68 NODAGA-CBP8 can be used to detect lung fibrosis, which is characterized by excess deposition of collagens, primarily type 1 collagen, and other extracellular matrix proteins in the parenchyma. 